\title{
CONCEPÇÕES DE ALFABETIZAÇÃO NAS DCNS E NA BNCC: DUAS LINHAS PARALELAS OU CONVERGENTES?
}

\author{
LITERACY CONCEPTIONS IN THE NATIONAL CURRICULUM GUIDELINES \\ (DCNS) AND THE NATIONAL COMMON CURRICULAR BASE (BNCC): \\ TWO PARALLEL OR CONVERGENT LINES?
}

\author{
Eloise Andréia dos Santos | Lattes | eloisesantoss@gmail.com \\ UFSC - PROFLETRAS \\ Éllen Lisbôa Moreira Ribeiro | Lattes | ellenelmr@gmail.com \\ UFSC - PROFLETRAS
}

\begin{abstract}
Resumo: As mudanças que o contexto educacional vem passando historicamente aparecem na sociedade contemporânea, sobretudo, no dilema da transição dos documentos norteadores da Educação Básica e em suas concepções de ensino, de sujeito e de alfabetização. Assim, este estudo objetivou fazer uma reflexão teórica e comparativa das concepções de alfabetização no documento Diretrizes Curriculares Nacionais da Educação Básica - DCNs (BRASIL, 2013) com o que se pode encontrar no documento que entrou em vigor em 2019, a Base Nacional Comum Curricular - BNCC (BRASIL, 2019a). Para tanto, buscou-se subsídios teóricos em pesquisadores consagrados da educação, como Duarte (2001), Mortatti (2006, 2007, 2010), Sebra e Dias (2011), entre outros autores, que têm estudado os métodos de alfabetização e sua hibridização na então chamada sociedade do conhecimento.
\end{abstract}

Palavras-chave: Alfabetização. DCNs. BNCC.

Abstract: The changes that the educational context has been going through historically appear in contemporary society, above all, in the dilemma of the transition of the guiding documents of Basic Education and in their conceptions of teaching, of subject and of literacy. Thus, this study aimed to make a theoretical and comparative reflection of literacy conceptions in the National Curriculum Guidelines for Basic Education - DCN-s (BRASIL, 2013) and inthe National Common Curricular Base - BNCC (BRASIL, 2019a), the document that came into force in 2019. To this end, theoretical supportwas sought from renowned researchers in the field of Education, such as Duarte (2001), Mortatti (2006, 2007, 2010), Sebra and Dias (2011), among other authors, who have studied the methods of literacy and its hybridization in the so-called knowledge society.

Keywords: Literacy. DCNs. BNCC. 


\section{INTRODUÇÃO}

A Educação Básica no Brasil e na sociedade letrada contemporânea tem se desenvolvido e reinventado, conforme as políticas públicas e documentos governamentais que a orientam em todas as suas etapas.

É um direito assegurado nas legislações vigentes, em especial na Constituição Federal, Estatuto da Criança e do Adolescente e Lei de Diretrizes e Bases da Educação Brasileira - Lei 9394/1996.

Nesse contexto, o sistema educacional brasileiro é reordenado por meio de documentos curriculares, dentre os quais podemos citar numa perspectiva mais recente: PCN's (BRASIL, 1997), DCNs (BRASIL, 2013) e o mais contemporâneo, que corresponde à BNCC (BRASIL, 2019a).

A alfabetização escolar, descrita por Mortatti (2010) como um processo de ensino e aprendizagem da leitura e escrita em língua materna, corresponde à fase inicial de escolarização das crianças, sendo, portanto, um processo complexo e multifacetado que envolve ações especificamente humanas e, consequentemente, políticas.

Essa etapa é caracterizada como dever do Estado e direito constitucional do cidadão, logo, tem uma relação muito importante com a inserção dos alfabetizados no mundo público, histórico, social e cultural. Ou seja, corresponde ao início da formação humana formal dos sujeitos, a partir do que até então era concebido como função social da escola. Trata-se, pois, de uma importante etapa, uma vez que “[...] há que se reconhecer que os indivíduos não nascem humanos, mas humanizam-se em condições sociais de vida e de educação" (DUARTE; MARTINS, 2013, p. 54).

A história da alfabetização no Brasil tem sua face mais visível no final do século XIX, quando pesquisadores e estudiosos passaram a refletir sobre os métodos "antigos" e "novos", buscando explicações para a dificuldade das crianças em aprender a ler e a escrever na escola pública (MORTATTI, 2006) o que desencadeou um processo de análises e discussões que emergiu nesse período em resposta ao grande índice de analfabetismo no Brasil (ROCHA; RIBEIRO, 2017).

Mortatti (2006) aponta que a alfabetização foi, durante muito tempo, articulada às demandas do mercado, em uma relação direta com o poder hegemônico de sociedade. Dessa forma, o ensino na alfabetização constituiu-se como um campo de disputas por métodos que, ao longo dos tempos, modificaram e modificam a forma de ensinar, mas não modificam o que ensinar, principalmente, nas escolas públicas. Para a autora, essa disputa por métodos limita a alfabetização e enraíza valores hegemônicos sobre as práticas de ensino. 
Entretanto, "as políticas de expansão e universalização da escolarização contribuíram para aumentar a relevância dessas discussões. Isso acontece tendo em vista os índices de analfabetismo presentes na sociedade expressos nos censos públicos" (BORDIGNON; PAIM, 2015, p. 90).

Essas pesquisas demonstraram que a alfabetização se constituiu como uma questão social relevante, por suas implicações político-econômicas e culturais, considerada um instrumento e veículo da política educacional que ultrapassa o âmbito da escola, mas que, muitas vezes, se torna inviabilizada pelas questões objetivas e subjetivas que perpassam o ambiente escolar.

Dessa forma, consideramos que, em meio aos diferentes fatores que influenciam nos resultados da alfabetização escolar, encontram-se atrelados desafios advindos de uma história de alfabetização que nem sempre estiveram voltados para o acesso universal, nem pelas políticas públicas de cada época, reflexos da concepção de alfabetização em cada momento histórico, nem pelos documentos governamentais norteadores.

Tendo em consideração a importância de tais documentos e de seus efeitos a partir da disseminação e formação de professores alfabetizadores, este artigo objetiva fazer uma comparação da concepção de alfabetização presente nas Diretrizes Curriculares Nacionais da Educação Básica -DCNs (BRASIL, 2013) com a concepção de alfabetização encontrada na Base Nacional Comum Curricular - BNCC (BRASIL, 2019a).

A próxima seção expõe a concepção de alfabetização apresentada pelas DCNs (BRASIL, 2013), em seguida, tem-se a BNCC (BRASIL, 2019a) com sua concepção sobre esse mesmo tema. Por fim, articula-se essas concepções comparando-as, conforme fundamentação teórica compatível a discussão sobre formação/emancipação humana.

\section{A CONCEPÇÃO DE ALFABETIZAÇÃO APRESENTADA PELAS DCNs}

Tomar a temática da alfabetização, definida por Maciel e Lucio (2009, p. 13) como "a aprendizagem inicial da leitura e da escrita", permite apreender sobre sua natureza política e social imbricada nos documentos governamentais.

Vale destacar que as Diretrizes Curriculares Nacionais (BRASIL, 2013) foram normas obrigatórias para a Educação Básica que orientaram o planejamento curricular das escolas e dos sistemas de ensino até a vigência da BNCC (BRASIL, 2019a).

As referidas diretrizes correspondem aoParecer CNE/CEB no 4/98 e Resolução CNE/CEB n²/98, regulamentadas desde 1998, emergiram numa acurada revisão com vistas à atualização de seus fundamentos, bases e princípios norteadores para as redes de ensino. 
Assim, as DCNs foram discutidas, concebidas e fixadas pelo Conselho Nacional de Educação (CNE), e sofreram, ao longo dos anos e das disputas hegemônicas, alterações mediante decretos e resoluções. Entre estas, destaca-se a resolução $\mathrm{N}^{\circ} 7$, de 14 de dezembro de 2010 (BRASIL, 2010), que fixou diretrizes curriculares nacionais para o Ensino Fundamental de 9 (nove) anos.

Rocha e Ribeiro (2017) complementam a respeito:

\begin{abstract}
A Resolução no7, de 14 de dezembro de 2010, articulada com as Diretrizes Curriculares Nacionais Gerais para a Educação Básica (Parecer CNE/CEB no 7/2010 e Resolução CNE/CEB no 4/2010), apresentou as Diretrizes Curriculares Nacionais para o Ensino Fundamental de Nove anos a serem observadas na organização curricular dos sistemas de ensino e de suas unidades escolares. Reúnem princípios e orientações estabelecidos pelo Conselho Nacional de Educação, para direcionar as políticas públicas educacionais, a forma de implementação e avaliação das orientações curriculares nacionais, das propostas curriculares dos Estados, do Distrito Federal, dos Municípios, e dos projetos político-pedagógicos das escolas (ROCHA; RIBEIRO, 2017, p. 8).
\end{abstract}

A principal mudança dessa resolução foi a alteração para nove anos do Ensino Fundamental, que significou principalmente uma ampliação do período destinado ao processo de alfabetização, já em tentativa de reverter a situação do analfabetismo brasileiro.

À alfabetização, ou como muitos passaram a se referir: "bloco da alfabetização", ficou determinado sua focalização especificamente nos três anos iniciais do Ensino Fundamental, ampliando e intensificando, gradativamente, o processo educativo com qualidade social, iniciado na Educação Infantil.

Assim, esse processo deve assegurar:

I - o desenvolvimento da capacidade de aprender, tendo como meios básicos o pleno domínio da leitura, da escrita e do cálculo;

II - foco central na alfabetização, ao longo dos três primeiros anos, conforme estabelece o Parecer CNE/CEB n 4/2008, de 20 de fevereiro de 2008, da lavra do conselheiro Murílio de Avellar Hingel, que apresenta orientação sobre os três anos iniciais do Ensino Fundamental de nove anos [...]. (BRASIL, 2013, p. 38).

Em conformidade com o referido parecer de fevereiro de 2008, as Diretrizes enquadraram a alfabetização principalmente nos três primeiros anos do Ensino Fundamental. Entretanto, tal enquadramento não significou que, no decorrer dos anos escolares an- 
teriores ou posteriores a esse período, os educandos não fossem estimulados para essa formação em prol da leitura e da escrita, visto que a perspectiva trazida foi um "processo de alfabetização" e não um fim/resultado para etapas consecutivas ou fases educativas.

Significa, pois, que, nos três primeiros anos escolares, a atenção centrou-se em práticas de ensino e aprendizagem, voltadas para a correspondência fonema-grafema, da percepção da língua (código), do agrupamento de letras em sílabas, sucessivamente de sílabas em palavras, entretanto, as práticas metodológicas não se restringem somente a isso.

Apontaríamos que essas percepções são resultado de práticas de ensino com diferentes linguagens da comunicação humana, além de outros aspectos sociocognitivos atrelados à alfabetização e ao letramento:

[...] os anos do Ensino Fundamental de 9 (nove) anos não se reduzem apenas à alfabetização e ao letramento. Desde os 6 (seis) anos de idade, os conteúdos dos demais componentes curriculares devem também ser trabalhados. São eles que, ao descortinarem às crianças o conhecimento do mundo por meio de novos olhares, lhes oferecem oportunidades de exercitar a leitura e a escrita de um modo mais significativo [...]. (BRASIL, 2013, p. 121).

Destacamos, ainda, a apropriação da escrita e das linguagens por meio de práticas sociais construídas no campo das interações históricas e culturais, ou seja, domínios linguísticos, elaborados socialmente pelos educandos via mediação dos professores.

Para entender a concepção de alfabetização que as Diretrizes assumiram, é fundamental entender o fundamento vinculado ao Ensino Fundamental e às orientações gerais da Educação Básica, que, por sua vez, relaciona-se ao direito à educação dos diferentes grupos sociais, direito esse associado ao exercício da cidadania. Logo, implica ver a educação como um processo de desenvolvimento do potencial humano, em seu caráter emancipatório (BRASIL, 2013).

Atrelado a esse fundamento, estão os princípios das DCNs e consequentemente da postura das escolas mediante as políticas educativas e suas ações pedagógicas. Os seguintes princípios foram norteadores da educação básica a partir das DCNs:

Éticos: de justiça, solidariedade, liberdade e autonomia; de respeito à dignidade da pessoa humana e de compromisso com a promoção do bem de todos, contribuindo para combater e eliminar quaisquer manifestações de preconceito e discriminação;

Políticos: de reconhecimento dos direitos e deveres de cidadania, de respeito ao bem comum e à preservação do regime democrático e dos recursos ambientais; de busca da equidade no acesso à educação, à 
saúde, ao trabalho, aos bens culturais e outros benefícios; de exigência de diversidade de tratamento para assegurar a igualdade de direitos entre os alunos que apresentam diferentes necessidades; de redução da pobreza e das desigualdades sociais e regionais;

Estéticos: de cultivo da sensibilidade juntamente com o da racionalidade; de enriquecimento das formas de expressão e do exercício da criatividade; de valorização das diferentes manifestações culturais, especialmente as da cultura brasileira; de construção de identidades plurais e solidárias (BRASIL, 2013, p. 107-108).

Dessa forma, a alfabetização enquanto processo de ensino e início formal da aprendizagem da leitura/escrita é retratada nas DCNs como continuidade do processo de desenvolvimento e de formação humana. Significa dizer que, atrelado a esse desenvolvimento, ocorre um processo de emancipação do sujeito social histórico e cultural.

Fundamentadas em Leontiev (1983), Mortatti (2006) e Vygotski (1993), autores que defendem a perspectiva histórico-cultural, acreditamos na inter-relação entre alfabetização-desenvolvimento-emancipação. Logo, ao vermos a alfabetização como um processo de emancipação e seguindo o pensamento desses autores, destacamos que esse ciclo não se reduz às esferas da vida cotidiana da criança, muito menos a uma fase pragmática da sua vida escolar.

Ao contrário, é uma atividade educativa de natureza política, social e cultural que possibilita a elaboração de conceitos com potencial para interferir na libertação da criança para o mundo da linguagem, ou seja, é uma fase de apropriações de conceitos, particularmente de conceitos científicos, numa dinâmica do mundo objetivado que implica não somente a compreensão da realidade, mas a concepção elaborada sobre ela (MARTINS, 2013).

A ideia de emancipação é atrelada à formação humana, logo a alfabetização constitui-se como instrumento para desencadear tais efeitos, como também para a inclusão social do sujeito.

Essa questão da formação/aprimoramento do gênero humano tem visibilidade nas DCNs em toda sua organização enquanto documento norteador que foi para as redes de ensino da educação básica. Assim, o documento abordava:

[...] a formação básica nacional relacionando-a com a parte diversificada, e com a preparação para o trabalho e as práticas sociais, consiste, portanto, na formulação de princípios para outra lógica de diretriz curricular, que considere a formação humana de sujeitos concretos, que vivem em determinado meio ambiente, contexto histórico e sociocultural, com suas condições físicas, emocionais e intelectuais. (BRASIL, 2013, p. 13). 
Percebe-se a noção de formação humana associada à questão do trabalho e das práticas sociais dentro de um contexto que é social, histórico e cultural. Portanto, a humanização do sujeito a partir da educação, formação e conhecimento, oportunizados e mediados no ambiente escolar.

Segundo Castilho (2013), a alfabetização como um direito, está vinculada ao direito à educação e ao pleno desenvolvimento da personalidade humana, previsto no art. 26 da Declaração Universal dos Direitos Humanos (1948). Assim, a alfabetização como um direito, está integrada às relações e oportunidades de educação formal e informal permanentes de modo a assegurar a todas as crianças, além do acesso e permanência na escola, uma efetiva alfabetização e, consequentemente, a promoção de uma inclusão social.

A perspectiva de uma alfabetização emancipatória permite ainda uma visão do sujeito em formação para sua essência humana, que constitui sua identidade histórica, social e cultural, reconhecendo os direitos enquanto cidadão e que respeita a diversidade em todos os seus sentidos (como referenciado nos princípios da ética, da estética e da política) (BRASIL, 2013).

Conforme encontra-se nas DCNs, "significa compreender que o direito à educação parte do princípio da formação da pessoa em sua essência humana" (BRASIL, 2013. p. 17). Significa, portanto, permitir que o sujeito em processo de alfabetização tenha acesso a uma aprendizagem progressiva de sistematização e aprofundamento das aprendizagens básicas, imprescindíveis para o prosseguimento dos estudos. Nesse aspecto, segundo as DCNs (BRASIL, 2013, p. 124), os três anos iniciais do Ensino Fundamental devem assegurar:

\footnotetext{
a) a alfabetização e o letramento;

b) o desenvolvimento das diversas formas de expressão, incluindo o aprendizado da Língua Portuguesa, a Literatura, a Música e demais artes, a Educação Física, assim como o aprendizado da Matemática, de Ciências, de História e de Geografia;

c) a continuidade da aprendizagem, tendo em conta a complexidade do processo de alfabetização e os prejuízos que a repetência pode causar no Ensino Fundamental como um todo, e, particularmente, na passagem do primeiro para o segundo ano de escolaridade e deste para o terceiro.
}

Nesse sentido, a concepção da alfabetização é retratada numa dimensão simbólica, expressiva e cultural em processo, em que as crianças são estimuladas a realizarem atividades sistemáticas, organizadas de tal forma, que sejam exploradas diferentes formas de representação e expressão infantis, ampliadas gradativamente, até que possibilitem a 
compreensão do que vem a ser a leitura e a escrita, para que façam uso desse objeto cultural.

De acordo com Vygotski (1993), a aquisição da linguagem escrita decorre da apropriação de um sistema de símbolos e signos, inicialmente de segunda ordem. O simbolismo de primeira ordem implica nos elementos que contribuíram para que a criança chegasse à escrita, como exemplo os gestos, o brinquedo, o desenho e a fala, elementos que antecedem a escrita.

Luria (1988) complementa explicando que todo ato de escrita é um simbolismo que pode ser de primeira ou se segunda ordem, isso dependerá do processo de desenvolvimento da alfabetização e consequentemente da escrita na criança. Logo, de primeira ordem, os traços, rabiscos e desenhos, elementos que representam o conceito desejado, sem intervenção do pensamento da criança, o que, com o tempo, passa a ser simbolismo de segunda ordem, mediado pela palavra como elo entre a ideia e a escrita.

A questão da expressão implica nas diferentes formas de expressão a serem exploradas nas práticas de ensino, que consequentemente advém das práticas sociais, conforme explica Bakhtin (2006, p. 106):

Não é a atividade mental que organiza a expressão, mas, ao contrário, é a expressão que organiza a atividade mental, que a modela e determina sua orientação. Qualquer que seja o aspecto da expressão-enunciação considerado, ele será determinado pelas condições reais da enunciação em questão, isto é, antes de tudo pela situação social mais imediata.

Compreende-se que a concepção de alfabetização das DCNs está dentro do que é preconizado na citação de Bakhtin (2006) transcrita anteriormente, porque os aspectos sócio-históricos, ou seja, transformações culturais, sociais, econômicas e tecnológicas consequentes do processo de aculturação e participação no processo de ensino, relacionam-se com a aquisição e a difusão da leitura e da escrita como processo histórico e político. As DCNs destacam também que: "A educação é, pois, processo e prática que se concretizam nas relações sociais que transcendem o espaço e o tempo escolares" (BRASIL, 2013, p. 16).

No decorrer das DCNs, encontramos referências a essa concepção, como pode ser observado na citação a seguir:

O acesso ao Ensino Fundamental aos 6 (seis) anos permite que todas as crianças brasileiras possam usufruir do direito à educação, beneficiandose de um ambiente educativo mais voltado à alfabetização e ao letramento, 
à aquisição de conhecimentos de outras áreas e ao desenvolvimento de diversas formas de expressão, ambiente a que já estavam expostas as crianças dos segmentos de rendas média e alta e que pode aumentar a probabilidade de seu sucesso no processo de escolarização (BRASIL, 2013, p. 111).

As DCNs recomendam enfaticamente que os sistemas de ensino adotem nas suas redes de escolas a organização em ciclo dos três primeiros anos do Ensino Fundamental, abrangendo crianças de 6 (seis), 7 (sete) e 8 (oito) anos de idade e instituindo um bloco destinado à alfabetização.

A apreensão da concepção de alfabetização das DCNs implica uma interpretação das bases teóricas e filosóficas que constituem o referido documento, indicando, portanto, que a concepção está submetida a partir dessas bases.

Em contraposição ao construtivismo, nas DCNs, encontramos os fundamentos da Teoria Histórico-Cultural (THC), que, por sua vez, tem como base filosófica o materialismo histórico-dialético ${ }^{1}$.

Dentre os trechos do referido documento que se articulam com tais fundamentos, destacamos que o direito à educação é apontado como fundamento maior destas Diretrizes: "Esse direito está fortemente associado ao exercício da cidadania, uma vez que a educação como processo de desenvolvimento do potencial humano garante o exercício dos direitos civis, políticos e sociais." (BRASIL, 2013, p. 105).

Tais fundamentos são defendidos por Vygotski (1993) e remetem ao desenvolvimento da capacidade humana, concebendo o sujeito como sócio-histórico, perspectiva adotada até então, para o aluno no contexto escolar brasileiro.

O processo de humanização acontece com a apropriação, pelo homem, da experiência sócio-histórica, onde os conhecimentos são adquiridos durante o desenvolvimento das faculdades humanas ao longo do processo histórico vivido (LEONTIEV, 1983). O que pode ser vislumbrado no seguinte trecho das DCNs:

Os conhecimentos escolares podem ser compreendidos como o conjunto de conhecimentos que a escola seleciona e transforma, no sentido de torná-los passíveis de serem ensinados, ao mesmo tempo em que servem de elementos para a formação ética, estética e política do aluno (BRASIL, 2013, p. 112).

\footnotetext{
${ }^{1}$ Materialismo histórico-dialético: concepção filosófica com enfoque teórico, metodológico e analítico para compreender a dinâmica e as grandes transformações da história e das sociedades humanas. $\mathrm{O}$ termo materialismo diz respeito à condição material da existência humana, enquanto, o termo histórico parte do entendimento de que a compreensão da existência humana implica na apreensão de seus condicionantes históricos. Por fim, o termo dialético que permite conhecer a realidade concreta em seu dinamismo e nas inter-relações. Nessa perspectiva, a tarefa da ciência está orientada para a crítica dos interesses e para a emancipação do homem (TRIVIÑOS, 2009, p. 21-23).
} 
Logo, a alfabetização no Ensino Fundamental precisa articular-se com os conhecimentos já adquiridos pelos alunos durante a Educação Infantil. Igualmente, o processo de alfabetização e letramento, com o qual ele passa a estar mais sistematicamente envolvido, não pode sofrer interrupção, o que se reporta à promoção da aprendizagem do ponto de vista das exigências sociais e de desenvolvimento pessoal.

Quanto aos fundamentos teórico-metodológicos da THC, estes se referem à essência do conhecimento em todas as suas dimensões, ontológica, gnosiológica, lógica e epistemológica, que tem como gênese os princípios do materialismo dialético e histórico (BARBOSA; MULLER; MELLO; 2016).

Compreende-se que estes princípios são o potencial da teoria em discussão, na medida em que favorecem a explicação da realidade concreta e as possibilidades existentes para a sua transformação, por meio da atividade humana organizada visando a um fim, que é o desenvolvimento humano nos aspectos social e individual (BARBOSA; MULLER; MELLO, 2016).

É perceptível que a alfabetização no ponto de vista das DCNs está ancorada na THC, sendo constituída como um dos meios pelo qual o sujeito se desenvolve e se apropria do conhecimento que amplia suas relações sociais, configurando a alfabetização como instrumento de emancipação social, política, histórica e cultural.

Para orientar sobre o currículo do Ensino Fundamental, as DCNs (BRASIL, 2013) retomam o Art. $9^{\circ}$ da Resolução CNE/CEB 7/2010 referente ao Ensino Fundamental de 9 (nove) anos. Esse diálogo relaciona-se com os pressupostos da THC:

Art. $9^{\circ} \mathrm{O}$ currículo do Ensino Fundamental é entendido, nesta Resolução, como constituído pelas experiências escolares que se desdobram em todo o conhecimento, permeadas pelas relações sociais, buscando articular vivências e saberes dos alunos com os conhecimentos historicamente acumulados e contribuindo para construir a identidade dos estudantes (BRASIL, 2013, p. 132).

Assim, a construção da identidade dos alunos é constituída, sobretudo, de experiências advindas das suas relações sociais, que dialogam, por sua vez, com os conhecimentos acumulados historicamente pela humanidade. É nesta questão que se encontra a função da escola, apontada nas palavras de Oliveira (2016): “[...] relaciona-se mais a uma elevação cultural e qualificação da consciência, do que à aquisição de bens econômicos, é nesse ponto que se encontra o cerne da função da escola, em especial da alfabetização" (OLIVEIRA, 2016, p. 41). 
As DCNs apresentam que a alfabetização não se restringe apenas a habilidades mecânicas de (codificar/decodificar), nem à aplicação repetitiva de escrita, leitura e cálculo fragmentados ou descontextualizados. Logo, esse percurso se assenta como uma ampliação do que a criança traz da Educação Infantil e do seu ambiente familiar, ou seja, respeitando suas características sociais e culturais:

A entrada de crianças de 6 (seis) anos no Ensino Fundamental implica assegurar-lhes garantia de aprendizagem e desenvolvimento pleno, atentando para a grande diversidade social, cultural e individual dos alunos, o que demanda espaços e tempos diversos de aprendizagem. $\mathrm{Na}$ perspectiva da continuidade do processo educativo proporcionada pelo alargamento da Educação Básica, o Ensino Fundamental terá muito a ganhar se absorver da Educação Infantil a necessidade de recuperar o caráter lúdico da aprendizagem, particularmente entre as crianças de 6 (seis) a 10 (dez) anos que frequentam as suas classes, tornando as aulas menos repetitivas, mais prazerosas e desafiadoras e levando à participação ativa dos alunos. A escola deve adotar formas de trabalho que proporcionem maior mobilidade às crianças na sala de aula, explorar com elas mais intensamente as diversas linguagens artísticas, a começar pela literatura, utilizar mais materiais que proporcionem aos alunos oportunidade de racionar manuseando-os, explorando as suas características e propriedades, ao mesmo tempo em que passa a sistematizar mais os conhecimentos escolares (BRASIL, 2013, p. 121).

A citação permite a compreensão de que a alfabetização enquanto processo seria uma garantia de que a passagem da Pré-Escola para o Ensino Fundamental não ignorasse os conhecimentos que a criança já adquiriu. Dessa forma, continuamente o processo de alfabetização e letramento, com o qual o educando passa a estar mais sistematicamente envolvido, não pode sofrer interrupção ao final do primeiro ano desse período escolar.

As DCNs (BRASIL, 2013) exploram sobre a diversidade dos sujeitos escolares quanto ao tempo de aprendizagem, pois, como há crianças que depois de alguns meses estão alfabetizadas, outras requerem de dois a três anos para consolidar suas aprendizagens básicas, o que tem a ver, muito frequentemente, com seu convívio em ambientes em que os usos sociais da leitura e escrita são intensos ou escassos, assim como com o próprio envolvimento da criança com esses usos sociais na família e em outros locais fora da escola.

Os procedimentos metodológicos apresentados para a alfabetização apontam para uma proposta plural, ou seja, não se detém a um único método de ensino para alfabetizar, uma vez que o processo depende de muitos fatores extraescolares e intraescolares. 
A apropriação tanto da leitura como da escrita decorre do horizonte axiológico dos educandos e dos saberes como: decodificação das letras, consciência fonológica, segmentação de palavras, correspondência entre signos/significados, entre outros. Esses fatores emanam do processo de alfabetização, sendo consequência e não condição para que o mesmo ocorra.

Essa proposta das DCNs é perceptível na citação a seguir e fica evidente que o foco é a aprendizagem, para isso, as redes deveriam partir das necessidades apresentadas pelos alunos, para o desenvolvimento de metodologias e estratégias variadas que melhor respondessem às diferenças de aprendizagem entre os estudantes e às suas demandas:

[...] a escola, no desempenho das suas funções de educar e cuidar, deve acolher os alunos dos diferentes grupos sociais, buscando construir e utilizar métodos, estratégias e recursos de ensino que melhor atendam às suas características cognitivas e culturais (BRASIL, 2013, p. 113).

Assim, na abordagem do currículo, as redes com sua autonomia e considerando suas realidades e sujeitos de ensino, levariam em conta a diversidade sociocultural da população escolar, as desigualdades de acesso ao consumo de bens culturais e a multiplicidade de interesses e necessidades.

Finalizando, compreendemos que os avanços da psicologia refletiram significativamente nos rumos da educação e na compreensão das capacidades a serem desenvolvidas para, com isso, entender como as crianças aprendem. Essa dimensão é importante para a ótica da educação contemporânea e os desafios que ela traz.

Em sequência, são apresentadas particularidades das origens da BNCC, sua organização e contexto epistemológico e teórico da alfabetização no documento.

\section{ALFABETIZAÇÃO SOB A ÓTICA DA BNCC}

A Constituição Federal - CF (BRASIL,1988) em seu Artigo 205, afirma que a educação é direito de todos e dever do Estado e da família. Ainda em relação a essa temática, em seu Artigo 210, a Carta Constitucional determina que sejam fixados conteúdos mínimos a serem trabalhados com a finalidade de garantir a formação básica comum aos estudantes.

Complementando, tem-se a Lei de Diretrizes e Bases - LDB, que no Artigo 9o, Inciso IV, ressalta ser de responsabilidade da União: 
[...] estabelecer, em colaboração com os Estados, o Distrito Federal e os Municípios, competências e diretrizes para a educação infantil, o ensino fundamental e o ensino médio, que nortearão os currículos e seus conteúdos mínimos, de modo a assegurar formação básica comum [... $]$ (BRASIL,1996; grifo das autoras).

Posteriormente, a Lei 13.005/2014, proclamou o Plano Nacional da Educação - PNE estabelecendo que a União pactuada com os Estados, o Distrito Federal e os Municípios devem estabelecer e implementar tanto as diretrizes pedagógicas, como a base nacional comum dos currículos, definindo ainda, os direitos e os objetivos de aprendizagem e desenvolvimento para cada ano da Educação Básica, resguardando as diversidades de âmbito regional, estadual e local (BRASIL, 2014).

Emerge, nesse cenário, a Base Nacional Comum Curricular (BRASIL, 2019a) como documento oficial que normatiza as aprendizagens essenciais que os discentes brasileiros devem adquirir e aprimorar.

Aprendizagens essas apontadas como condições para o desenvolvimento das competências gerais, definidas pela própria base e apresentadas como sendo viabilizadoras para o resguardo do direito de aprendizagem e desenvolvimento do aluno (BRASIL, 2019a, p.7).

O documento traz como objetivo de aprendizagem para a educação brasileira desenvolver dez Competências Gerais da Educação Básica. Com a finalidade de atingir esse propósito, a Base apresenta Competências Específicas para as diversas áreas do conhecimento nas quais estão inseridos os componentes curriculares previstos para os ensinos Fundamental e Médio.

Para as áreas que possuem mais de um componente curricular, a BNCC apresentou a seguinte proposta:

Nas áreas que abrigam mais de um componente curricular (Linguagens e Ciências Humanas), também são definidas competências específicas do componente (Língua Portuguesa, Arte, Educação Física, Língua Inglesa, Geografia e História) a ser desenvolvidas pelos alunos ao longo dessa etapa de escolarização (BRASIL, 2019a, p. 28).

Para consubstanciar a relação entre ensino e aprendizagem de cada componente, foram definidas habilidades (que apresentam as aprendizagens essenciais) a serem devidamente complementadas pelos currículos, juntamente à intenção de proporcionar aos alunos o desenvolvimento, tanto das competências específicas, como das competências gerais. 
BNCC e currículos têm papéis complementares para assegurar as aprendizagens essenciais definidas para cada etapa da Educação Básica, uma vez que tais aprendizagens só se materializam mediante o conjunto de decisões que caracterizam o currículo em ação. São essas decisões que vão adequar as proposições da BNCC à realidade local, considerando a autonomia dos sistemas ou das redes de ensino e das instituições escolares, como também o contexto e as características dos alunos (BRASIL, 2019a. p. 16).

Em relação à questão da autonomia exposta no trecho anterior, a BNCC (BRASIL, 2019a) sinaliza que apesar de definir as aprendizagens essenciais, não direciona para determinadas abordagens ou metodologias específicas, preservando assim a autonomia dos sistemas e das redes de ensino, devendo os currículos estarem adaptados a cada realidade.

O documento se propõe a nortear o que deve ser ensinado nas escolas, ficando a cargo das redes e dos sistemas a definição de como serão garantidas essas aprendizagens. No entanto, no que diz respeito à alfabetização, podemos considerar que essa isenção é relativa.

[...] 'codificar e decodificar' os sons da língua (fonema) em material gráfico (grafemas ou letras), o que envolve o desenvolvimento de uma consciência fonológica (dos fonemas do português do Brasil e de sua organização em segmentos sonoros maiores como sílabas e palavras) [...] (BRASIL, 2019a, p. 90; grifo das autoras).

Atentemos que o documento em questão faz referência aos métodos sintéticos de alfabetização, uma vez que sinaliza a utilização de: "procedimentos que partem de unidades menores para chegar a unidades maiores (da parte para o todo)" (SEBRA; DIAS, 2011, p.1).

No trecho apresentado, a BNCC faz menção à necessidade do desenvolvimento da consciência fonológica, sendo esta considerada a partir da apropriação dos fonemas (menores unidades apresentadas), posteriormente das sílabas e, em seguida, das palavras (unidades de sentido), assim como preconizam os métodos sintéticos.

No que diz respeito a esses métodos, cabe salientar que são criticados por enfatizar a repetição e a memorização, além de não se aproximar do "uso social da escrita", como apontado por Gonçalves (2011, p.52).

Ao considerarmos que a BNCC apresenta o fonema como sendo a unidade mínima de análise da relação escrita-fala, observa-se uma aproximação ao método fônico, o 
que para Sebra e Dias (2011) pode ser visto como característica principal desse método. Segundo as autoras: "O método fônico tem como objetivo principal ensinar as correspondências grafofonêmicas e desenvolver habilidades metafonológicas, fomentado as habilidades de decodificação e codificação” (SEBRA e DIAS, 2011, p.5).

A alfabetização é apresentada na BNCC (BRASIL, 2019a) como um processo que se constitui o foco da ação pedagógica nos dois primeiros anos do Ensino Fundamental.

Nesse processo, é preciso que os estudantes conheçam o alfabeto e a mecânica da escrita/leitura - processos que visam a que alguém (se) torne alfabetizado, ou seja, consiga 'codificar e decodificar' os sons da língua (fonema) em material gráfico (grafemas ou letras) [...](BRASIL, 2019a, p. 90; grifo das autoras).

Essa visão simplista e mecanizada da alfabetização, tal como é difundida pela Base, faz contraponto à concepção de alfabetização apresentada por Gontijo (2002):

[...] processo pelo qual os indivíduos tomam para si o resultado do desenvolvimento histórico-social (linguagem escrita), a fim de desenvolver as possibilidades máximas da humanidade, como por exemplo, da universalidade e liberdade do homem (GONTIJO, 2002, p. 41).

Corroborando com a perspectiva histórico-cultural da alfabetização, apresentamos as palavras de Vygotski (2000):

[...] o domínio deste sistema complexo não pode realizar-se por uma via exclusivamente mecânica, desde fora, por meio de uma simples pronunciação, de uma aprendizagem artificial. [...] O domínio da linguagem escrita é, na realidade, o resultado de um largo desenvolvimento das funções psíquicas superiores[...] (VYGOTSKI, 2000, p.184; grifo das autoras).

Ao expor as habilidades propostas para os dois primeiros anos do Ensino Fundamental, a BNCC (BRASIL, 2019a, p.93) as define como "capacidades/habilidades envolvidas na alfabetização/ como sendo capacidades de (de)codificação”, demarcando desta forma, uma fase específica para esse período.

A partir dessa definição, podemos inferir que a concepção de alfabetização do documento não a compreende como instrumento de emancipação social, política, histórica e cultural, haja vista que seu conceito foi reduzido à mera codificação e decodificação em uma etapa ou fase específica, distanciando-se da ideia de processo contínuo de desenvolvimento. 
A alfabetização na BNCC, assim como todo o Ensino Fundamental e Médio, está centrada no desenvolvimento de competências/habilidades. Essa proposta de ensino está ancorada na Pedagogia das Competências, amplamente defendida por Philippe Perrenoud, autor do livro "Construir competências desde a escola" (1999).

Esse ancoramento fica explícito na apresentação dos fundamentos pedagógicos da própria Base, como exposto a seguir:

O conceito de competência, adotado pela BNCC, marca a discussão pedagógica e social das últimas décadas e pode ser inferido no texto da LDB, especialmente quando se estabelecem as finalidades gerais do Ensino Fundamental e do Ensino Médio. [...] Ao adotar esse enfoque, a BNCC indica que as decisões pedagógicas devem estar orientadas para o desenvolvimento de competências (BRASIL, 2019a, p.13).

Para Duarte (2001,p. 35), a Pedagogia das Competências faz parte de uma corrente educacional amplamente difundida na atualidade e denominada por ele como: “Pedagogias do 'aprender a aprender"”.

Segundo esse autor, há convergência entre o construtivismo, o movimento escolanovista e as pedagogias do aprender a aprender na medida em que todos valorizam o conhecimento que o indivíduo constrói por si mesmo, a partir do conhecimento existente no mundo.

Esse ponto de convergência pode ser entendido por intermédio das palavras de Derisso (2010) sobre a base do construtivismo:

[...] A teoria do conhecimento de Jean Piaget sustenta-se na tese de que o conhecimento é um produto da atividade subjetiva e, como tal, só pode ser concebido como conhecimento de uma pessoa, ou seja: cada pessoa constrói o seu próprio conhecimento, isso constitui a principal base para a pedagogia denominada construtivismo (DERISSO, 2010, p.56).

O mesmo autor sustenta a contribuição construtivista para a Pedagogia das Competências:

Na última década do século XX o construtivismo foi reelaborado e incorporado pela pedagogia das competências que tem em Phillip Perrenoud sua principal expressão pública. Nessa nova versão a pedagogia construtivista nos aparece mais pragmática, uma vez que coloca abertamente a preocupação com a adaptação do estudante à nova realidade do capitalismo globalizado (DERISSO, 2010, p.51). 
A Pedagogia das Competências encontra outra referência construtivista, além do exposto acima, posto que demonstra o entendimento que o homem necessita adaptar-se às inovações do mundo que o cerca, tanto em relação às questões tecnológicas, como em relação às questões dos hábitos. Essa afirmativa pode ser evidenciada mediante as ideias de Perrenoud (1999):

[...] a evolução do mundo, das fronteiras, das tecnologias, dos estilos de vida requer uma flexibilidade e criatividade crescentes dos seres humanos, no trabalho e na cidade. Nessa perspectiva, confere-se ocasionalmente à escola a missão prioritária de desenvolver a inteligência como capacidade multiforme de adaptação às diferenças e às mudanças (PERRENOUD, 1999, p.17).

Observe outro trecho, da mesma obra, que ratifica esse posicionamento:

Concebidas dessa maneira, as competências são importantes metas da formação. Elas podem responder a uma demanda social dirigida para a adaptação ao mercado $e$ às mudanças e podem fornecer os meios para apreender a realidade e não ficar indefeso nas relações sociais. (PERRENOUD, 1999, p.32; grifo das autoras).

Assim como a Pedagogia das Competências, a própria BNCC, além de estar fundamentada na adaptabilidade, também encontra respaldo no lema tecnicista do "saber fazer”. Esse amparo pode ser evidenciado na fundamentação pedagógica do próprio documento:

[...] Por meio da indicação clara do que os alunos devem "saber" (considerando a constituição de conhecimentos, habilidades, atitudes e valores) e, sobretudo, do que devem "saber fazer" (considerando a mobilização desses conhecimentos, habilidades, atitudes e valores para resolver demandas complexas da vida cotidiana, do pleno exercício da cidadania e do mundo do trabalho) [...](BRASIL, 2019a, p.13).

Nesse trecho, são visíveis os reflexos, na BNCC, da lógica tecnicista do saber fazer com a finalidade de satisfazer a lógica adaptativa, posto queas demandas exigidas pelo meio devem ser atendidas pelos sujeitos sob pena de ficarem à margem do mundo do trabalho e da própria sociedade.

Partindo-se do pressuposto que a Pedagogia das Competências está situada entre as Pedagogias do Aprender a Aprender, assim como apontado por Duarte (2001), pode- 
-se inferir que essa pedagogia não somente incorporou referências do construtivismo e do tecnicismo, como também incorporou outras bases referenciais como o racionalismo, o individualismo e o neopragmatismo, apontados por Araujo (2004).

Mediante a perspectiva do tecnicismo e da adaptabilidade, a alfabetização é entendida apenas como um requisito inicial para acessar postos de trabalho na sociedade contemporânea. Sendo necessária apenas como uma adaptação necessária (ou requisito) para que o sujeito tenha condições mínimas de atender às demandas do mercado de trabalho e do cuidado de si.

Ratificando essa ideia, Araujo (2004, p.15) afirma que "devemos ter em mente as possibilidades efetivas que a Pedagogia das Competências tem de promover o desenvolvimento amplo das capacidades dos trabalhadores".

Esse ponto de vista defende o entendimento que essa proposta de ensino é uma boa opção uma vez que apresenta possibilidades para viabilizar a formação de uma classe trabalhadora apta a atender às demandas do mercado de trabalho.

Se o objetivo único do ensino no Brasil for capacitar trabalhadores, essa opção pedagógica seria ótima, contudo, se a finalidade do ensino for contribuir para a democratização do conhecimento e para a formação de um cidadão crítico e situado historicamente, provavelmente essa escolha estaria equivocada.

Em relação a essa discussão, expomos o pensamento de Derisso (2010):

[...] as expectativas que o Estado e as classes dominantes mantém com relação aos resultados da educação escolar apontam para a formação de um cidadão pacífico, ordeiro e preparado para concorrer no mercado de trabalho, uma perspectiva muito distinta daquela que vê na escola a função de democratizar o conhecimento socialmente produzido pela humanidade para formar um cidadão crítico e habilitado a transformar a realidade social superando as mazelas da sociedade [...] (DERISSO, 2010, p.51-52).

Como forma de consolidar a premissa que a BNCC apresenta reflexos oriundos do construtivismo em sua concepção de alfabetização, apresentamos:

[...] alfabetizar é trabalhar com a apropriação pelo aluno da ortografia do português do Brasil escrito, compreendendo como se dá este processo (longo) de construção de um conjunto de conhecimentos sobre o funcionamento fonológico da língua pelo estudante (BRASIL, 2019a, p.90). 
Salientamos que para Gontijo (2002), o construtivismo deve ser ultrapassado uma vez que não considera a elaboração dos sentidos da alfabetização nem a dimensão discursiva da escrita. Sendo assim, a autora afirma que para o construtivismo "os níveis de evolução da escrita na criança somente são válidos com relação à análise de palavras.” (GONTIJO, 2002, p.14).

A pertinência das considerações de Gontijo (2002) é demonstrada a partir da definição de alfabetização apresentada pela BNCC: "processo básico (alfabetização) de construção do conhecimento das relações fonografêmicas” (BRASIL, 2019a, p. 91).

Ao apresentar essa definição ancorada no construtivismo, a Base evidencia que a proposta de alfabetização em vigor privilegia as relações entre as letras e os sons em detrimento ao estabelecimento das relações de sentido apresentadas no discurso.

Sobre o processo de alfabetização à luz do construtivismo, Mortatti (2007) afirma que é resultante:

[...] da construção, por parte da criança, do conhecimento sobre a leitura e a escrita, na interação com esse objeto de conhecimento (a língua escrita). A construção desse conhecimento ocorre de acordo com certas etapas, seguindo um processo de desenvolvimento de estruturas cognitivas que a criança possui naturalmente, sem depender de intervenções de ensino e de condições socioculturais. (MORTATTI, 2007, p. 162).

A partir dessa consideração, pode-se inferir que o professor, o ensino e o meio no qual o discente se constitui como sujeito tornam-se secundários no processo da alfabetização construtivista.

A proposição de uma alfabetização com bases epistemológicas assentadas no construtivismo não é algo proposto somente pela BNCC. Essa perspectiva já fora apresentada em outros momentos, conforme sinalizado por Mortatti (2006):

[... tornam-se hegemônicos o discurso institucional sobre o construtivismo e as propostas de concretização decorrentes de certas apropriações da teoria construtivista. E tem-se, hoje, a institucionalização, em nível nacional, do construtivismo em alfabetização, verificável, por exemplo, nos Parâmetros Curriculares Nacionais (PCNs), dentre tantas outras iniciativas recentes (MORTATTI, 2006, p.4; grifos das autoras).

Além do perceptível alinhamento da alfabetização proposta pela BNCC com os pressupostos construtivistas (tanto em relação ao fato de secundarizar o papel do professor posto que é considerado apenas como mediador/facilitador do processo de ensino 
e de aprendizagem, como em relação à lógica adaptativa que parte da premissa que o processo de alfabetização deve existir para viabilizar a capacitação dos sujeitos para que possam adentrar ao mercado de trabalho); pode-se observar também uma visão reducionista da concepção do que seja alfabetização, uma vez que a relaciona/considera como reles competência de decodificação de letras e de palavras.

Cabe-nos ressaltar que o conceito de alfabetização deve transcender essa visão simplista e reducionista de leitura técnica e mecânica com vistas à aquisição da norma padrão e ao desenvolvimento de uma competência.

Freire e Macedo (1994) discutem a respeito:

\begin{abstract}
Para que a ideia de alfabetização ganhe significado, deve ser situada dentro de uma teoria de produção cultural e encarada como parte integrante do modo pelo qual as pessoas produzem, transformam e reproduzem significado. A alfabetização deve ser vista como um meio que compõe eafirma os momentos históricos existenciais da experiência vivida(FREIRE; MACEDO, 1994, p. 90).
\end{abstract}

Em sequência, o próximo item traz uma breve comparação das concepções discutidas sob a luz dos referidos documentos norteadores, sendo, neste ponto, já perceptível a discrepância existente entre as abordagens de cada um.

\title{
4 DUAS LINHAS PARALELAS OU CONVERGENTES?
}

Linhas paralelas podem ser definidas como retas distintas que possuem o mesmo coeficiente angular, nunca se cruzam e não há ponto em comum entre elas.

Assim são as concepções de alfabetização aqui discutidas. A metáfora, que apresenta o título do artigo e o subtítulo dessa parte comparativa, foi colocada intencionalmente para refletirmos que, embora o objetivo seja desenvolvimento e formação na perspectiva da educação brasileira, as propostas da BNCC não apresentam concepções de ensino, de sujeito, nem de alfabetização, próximas das concepções trazidas pelas DCNs. Diferem-se e não se cruzam, porque os fundamentos e princípios os quais as embasam são divergentes.

Para uma melhor comparação dos apontamentos teóricos discutidos, tem-se o Quadro 1, que apresenta a concepção de alfabetização, a autonomia das redes ou sistemas de ensino, o método, a base epistemológica, e o tempo previsto para a alfabetização, conforme os documentos norteadores de ensino abordados. 
Quadro 1 - Quadro comparativo das concepções de alfabetização nas DCNs e na BNCC

\begin{tabular}{|c|c|c|}
\hline \multicolumn{3}{|c|}{ ALFABETIZAÇÃO } \\
\hline $\begin{array}{c}\text { ASPECTO } \\
\text { CONSIDERADO }\end{array}$ & DCN & BNCC \\
\hline $\begin{array}{c}\text { BASE } \\
\text { EPISTEMOLÓGICA }\end{array}$ & $\begin{array}{l}\text { Teoria Histórico- } \\
\text { Cultural/Materialismo } \\
\text { Histórico-Dialético }\end{array}$ & $\begin{array}{c}\text { Pedagogia das Competências/ } \\
\text { Construtivismo/ } \\
\text { Tecnicismo } \\
\text { Racionalismo/Individualismo/ } \\
\text { Neopragmatismo }\end{array}$ \\
\hline $\begin{array}{l}\text { CONCEPÇÃO DE } \\
\text { ALFABETIZAÇÃO }\end{array}$ & $\begin{array}{l}\text { Instrumento de emanci- } \\
\text { pação do sujeito social, } \\
\text { político, histórico e } \\
\text { cultural. }\end{array}$ & $\begin{array}{l}\text { Etapa básica de construção do } \\
\text { conhecimento das relações fono- } \\
\text { grafêmicas. }\end{array}$ \\
\hline MÉTODO & Plural (livre) & $\begin{array}{c}\text { Tendência aos } \\
\text { métodos sintético/fônico }\end{array}$ \\
\hline $\begin{array}{c}\text { TEMPO } \\
\text { PREVISTO PARA } \\
\text { ALFABETIZAÇÃO }\end{array}$ & 3 anos & 2 anos \\
\hline $\begin{array}{l}\text { AUTONOMIA DAS } \\
\text { REDES/SISTEMAS }\end{array}$ & Total & Relativa \\
\hline
\end{tabular}

Na BNCC (BRASIL, 2019a), a alfabetização deixa de ser vista como um processo, conforme demonstrado e orientado nas propostas das DCNs (BRASIL, 2013) e passa a ser focalizada como competência e habilidade adquirida como um fim na consciência fonológica.

Portanto, a alfabetização, indicada por muitos teóricos como um dos momentos cruciais para o desenvolvimento e formação dos sujeitos, representará práticas metodológicas de ensino voltadas para a marcha sintética, o que não representa uma prática ao todo negativa para o ensino-aprendizagem na contemporaneidade, entretanto, não deve restringir-se apenas a isso.

Faz-se necessário compreender que os Planos Nacionais de Educação buscaram preencher ao longo do tempo as lacunas previstas na LDB e na Constituição Federal. Os altos índices de analfabetismo incitaram o surgimento de estratégias, objetivos e metas que foram estabelecidas nos Planos Nacionais de Educação, visando melhorar tal realidade. 
O Plano Nacional de Educação - PNE (BRASIL, 2001), inicialmente publicado em 2001, foi baseado no Projeto de Lei 4.155/98 e emergiu num contexto de avanços e retrocessos, marcado por desafios e expectativas para o período de (2001-2010). Posteriormente, as metas foram reformuladas a partir de lacunas não cumpridas, para o período de (2014-2024).

Assim, através de uma proposta de universalização em várias questões, o PNE (2014-2024) foi estruturado em 14 artigos, 20 metas e 243 estratégias aprovados após longa agonia de anos, conforme apontaram Mélo e Fernandes (2014), o PNE foi sancionado pela Lei 13.005/2014, vigente a partir de 25 de junho de 2014.

Dentre as metas estabelecidas pelo PNE 2014-2024, as que se relacionam de forma direta com a questão da alfabetização preveem: universalidade do acesso, até 2016, de crianças entre 4 e 5 anos, bem como aumento da oferta de educação infantil para crianças até 3 anos; universalizar o Ensino Fundamental de 9 anos; universalizar o acesso de educandos entre 4 e 17 anos à Educação Básica e atendimento especializado em caso de transtornos, deficiências ou superdotação; alfabetizar todas as crianças até no máximo o $3^{\circ}$ ano do Ensino Fundamental; aumentar o acesso à educação integral; elevar a alfabetização das pessoas maiores de15 anos e qualificação profissional (BRASIL, 2014).

Todavia, a elevação da alfabetização ou a universalização de acesso à educação precisa estar articulada com políticas públicas e programas para uma sociedade mais democrática, a formação integral trazida pela proposta do plano remete à formação em prol da transformação da realidade/sociedade como era apontado nas concepções das DCNs, enquanto a formação da BNCC volta-se para competências, habilidade e adaptação ao meio/sociedade e preparação, sobretudo, para o mercado de trabalho. Ou apenas com a perspectiva de cumprir as metas do plano quantitativamente, visando reduzir os índices de analfabetismo. O que por sua vez, considera-se utopia (diante do tempo e proposta da BNCC) destinados à alfabetização, podendo implicar ainda numa hecatombe do processo de alfabetização.

Nessa perspectiva, que a crítica se apresenta significativa, a quem essa educação se destina? Que sujeito ela quer formar? Por que alfabetizar? A resposta parcial a essas indagações remete ao que Freire (2003) escreveu:

[...] ao sistema escolar não cabe somente a tarefa de alfabetizar. A escola precisa transformar o ser humano num ser verdadeiramente pensante, que faça elepassar da intransitividade para a transitividade. Ela precisa inquietar o homem e tirar do seu espírito o conformismo. O ser humano necessita urgentemente ter vontade de ter vontade. E isso só é possível 
se a escola fizer o seu papel de transformadora e disseminadora do conhecimento (FREIRE, 2003, p. 34).

Um ensino democrático significa assim, a democratização do próprio conhecimento sistematizado da história e cultura das sociedades. Logo, uma educação única para todos é aquela, onde haverá verdadeiramente a democratização do ensino. E, além da unicidade da educação, a missão dela, conforme Bittar e Ferreira Jr. (2008), é educar o ser humano por completo, omnilateralmente ${ }^{2}$.

Nas DCNs, letramento e leitura ultrapassam a percepção de código/decodificação da língua, responde a ideologias, horizontes axiológicos e formativos, que são supridos no contexto escolar, pela sociocognição, entre outros conhecimentos históricos e culturais imbricados nesse ato.

O processo de alfabetização começa antes da escola, e se estende gradativamente conforme o sujeito se desenvolve na sociedade, na sua comunidade e no mundo. A escola é o local destinado ao aprimoramento dessa formação de modo omnilateral.

Observemos que a Política Nacional da Alfabetização - PNA (BRASIL, 2019b), instituída por meio do Decreto no 9.765, de 11 de abril de 2019, mais recente documento federal referente à alfabetização no Brasil, deu continuidade a mudança das políticas públicas de ensino brasileiras iniciada pela BNCC.

A alteração das bases epistemológicas e da concepção de alfabetização apresentada pela BNCC em relação às DCNs foi reafirmada pela PNA, uma vez que o documento ratifica a tendência reducionista e simplista de alfabetização ao apresentar "a priorização da alfabetização no $1^{\circ}$ ano como uma das diretrizes da PNA” (BRASIL, 2019b, p.32).

As DCNs apresentaram 3 (três) anos para o ciclo da alfabetização, com a BNCC esse período foi reduzido para 2 (dois) anos, mais recentemente com a PNA a proposta apresentada é de 1 (um) ano somente. Isso posto, fica fácil a percepção de que essa redução do tempo dedicado à alfabetização possui sua origem no entendimento de que ler resume-se simplesmente em decodificar.

Outro aspecto importante a ser mencionado é a diminuição da autonomia do fazer pedagógico: nas DCNs, não havia indicação do método a ser utilizado para alfabetizar; na

\footnotetext{
${ }^{2}$ Omnilateralidade é um termo que se refere à formação humana oposta à formação unilateral provocada pelo trabalho alienado, pela divisão social do trabalho, pelas relações burguesas parciais, limitadas e perniciosas. Omnilateralidade se refere sempre a ruptura com o homem limitado da sociedade capitalista e deve ser ampla e radical. Para tanto, deve atingir uma gama muito variada de aspectos da formação do ser social, com expressões nos campos da moral, da ética, do fazer prático, da criação intelectual, artística, da afetividade, da sensibilidade, da emoção, entre outras (BITTAR; FERREIRA JR., 2008).
} 
BNCC, foi percebida uma tendência à utilização dos métodos sintético/fônico; na PNA, há exigência da utilização do método fônico, conforme apresentado em seus princípios basilares: “[...] a ênfase no ensino dos seis componentes essenciais para a alfabetização: consciência fonêmica, instrução fônica sistemática, fluência em leitura oral, desenvolvimento de vocabulário, compreensão de textos e produção escrita." (BRASIL, 2019b, p. 51).

Percebe-se que foi cerceada às escolas e aos docentes a escolha das metodologias e dos métodos de alfabetização que julgarem adequados para a realidade de ensino na qual estiverem inseridos.

Todas essas medidas, além de apresentarem um enrijecimento gradual das políticas públicas de alfabetização, também denotam um acentuado distanciamento da história recente da alfabetização brasileira, do letramento e do cuidado em se alfabetizar e ampliar as práticas de leitura e escrita simultaneamente, pois a PNA compactua com a noção de competência adotada na BNCC e reduz a alfabetização ao desenvolvimento da consciência fonológica, à marcha sintética e à aprendizagem da técnica da escrita com o objetivo de formar pessoas adaptadas às demandas sociais vigentes.

As implicações para o contexto escolar desta perspectiva reducionista da alfabetização são muitas, restando ao professor assentar sua prática educacional na "palavra" como unidade de ensino privilegiada, na sua decomposição/composição, na segmentação, levando o aluno a manipular sílabas, fonemas e seus correspondentes gráficos.

Não somos contrárias ao método fônico, mas sim à restrição da alfabetização a um único método e abordagem de ensino, pois as "evidências científicas" exploradas na PNA reforçam uma imposição generalista e simplista, na qual desconsideram a pluralidade de saberes dos docentes e das reais necessidades de aprendizagem dos alunos de múltiplos contextos escolares da Educação Básica do Brasil. Assim, a consciência fonológica é uma condição necessária, todavia não suficiente, para alfabetizar e esta perspectiva coincide com uma concepção dos seres humanos como genuínos executores de tarefas, ou seja, desconsidera o potencial humano de agir como um sujeito crítico no mundo.

Para terminar, remetemos a Tfouni (1997), que afirma que a alfabetização na educação brasileira, em meio às disputas hegemônicas de poder, necessita ser compreendida, pois, segundo a autora, ao longo da história, muitas vezes ela foi mal-entendida:

Há duas formas segundo as quais comumente se entende a alfabetização: ou como um processo de aquisição individual de habilidades requeridas para a leitura e escrita, ou como um processo de representação de objetos diversos, de naturezas diferentes. $\mathrm{O}$ mal-entendido que parece estar na 
base da primeira perspectiva é que a alfabetização é algo que chega a um fim, e pode, portanto, ser descrita sob a forma de objetivos instrucionais. Como processo que é parece-me antes que o que caracteriza a alfabetização é a sua incompletude (TFOUNI, 1997, p. 9).

Conforme as concepções de alfabetização analisadas nos documentos e apresentadas por Tfouni (1997) a educação brasileira enfrenta o dilema de entender a alfabetização como um fim em si mesma ou como um processo que se constitui ao longo da vida dos sujeitos.

\section{CONSIDERAÇÕES FINAIS}

A discussão realizada apresentou brevemente a concepção de alfabetização nos documentos norteadores da Educação Básica no Brasil, Diretrizes Curriculares Nacionais (BRASIL, 2013) e Base Nacional Comum Curricular (BRASIL, 2019a), com vistas à formação/emancipação humana.

A articulação de conceitos, fundamentos e princípios foi fundamental para a percepção da importância da alfabetização no desenvolvimento e formação das crianças da escola pública brasileira e os desafios que cada vez mais aumentam no contexto escolar contemporâneo.

Portanto, o processo de alfabetização, que notoriamente implica a ampliação das possibilidades de relação com a escrita, resulta de uma ampliação do que antecede a entrada da criança no espaço escolar; logo, não remete a somente adquirir o alfabeto, o código da língua escrita. É nessa perspectiva que a alfabetização precisa ser entendida, orientada e disseminada entre redes de ensino, gestores, equipes pedagógicas, alfabetizadores e educadores.

Embora as políticas públicas, por meio dos documentos mais recentes, tenham apresentado a alfabetização de modo simplista e padronizada, seus delineamentos, fundamentos e princípios precisam ser compreendidos e apropriados pelos profissionais da educação com a finalidade de favorecer a educação democrática e universal, que visa à formação ampla e humanizada dos alunos, levando em consideração as especificidades de cada contexto escolar.

Enfim, é fundamental compreender, mesmo que brevemente, a história, a organização e as concepções de alfabetização, nos documentos norteadores anteriores e atuais, de modo que educadores e estudiosos da área tenham condições de fomentar discussões necessárias à criação democrática e ao aprimoramento de políticas de alfabetização munici- 
pais que levem em consideração suas realidades, com vistas à preservação da autonomia das redes/escolas, assim como garantir o direito fundamental de educação para todos: pública, gratuita e de qualidade.

\section{REFERÊNCIAS}

ARAUJO, R. M. L. As referências da pedagogia das competências.Perspectiva, v.22, n.02, p.97-524, jul./dez. 2004. Disponível em: https://periodicos.ufsc.br/index.php/ perspectiva/article/viewFile/9664/8885. Acesso em: 24 jul. 2019.

BAKHTIN, M. Marxismo e filosofia da linguagem. 12. ed. São Paulo: Hucitec, 2006.

BARBOSA, M. V.; MULLER, Stela; MELLO, Suely Amaral. (org.) Teoria históricocultural: questões fundamentais para a educação escolar. Oficina Universitária. São Paulo: Cultura Acadêmica, 2016.

BITTAR, M.; FERREIRA JR., A. A educação na perspectiva marxista: uma abordagem baseada em Marx e Gramsci.Interface(Botucatu), vol.12, n.26, Botucatu July/Sept. 2008. Disponível em: http://www.scielo.br/scielo.php?script=sci_ arttext\&pid=S1414-32832008000300014. Acesso em 24 jul. 2019.

BORDIGNON, L. H. C.; PAIM, M. M. W. História e políticas públicas de alfabetização e letramento no Brasil: breves apontamentos com enfoque para o plano nacional de educação. Diálogos em Educação, Rio Grande do Sul: FURG, v. 24, n. 1. 2015. Disponível em: https://periodicos.furg.br/momento/article/view/5038. Acesso em: 27 jun. 2019.

BRASIL, Câmara de Educação Básica, Parecer CEB n 4/98 de 29 de janeiro de 1998. Diário Oficial da União, Brasília, DF, 30 mar. 1998.

BRASIL. Conselho Nacional de Educação. Câmara de Educação Básica. Resolução Noo. $n^{\circ}$ 2/98 de 7 de abril de 1998 que institui as Diretrizes Curriculares Nacionais para o Ensino Fundamental. Disponível em: http://portal.mec.gov.br/dmdocuments/resolucao_ ceb_0298.pdf. Acesso em: 27 jun. 2019.

BRASIL, Constituição da República Federativa do Brasil. Brasília, DF: SenadoFederal, 1988.

BRASIL. Lei no 10.172, de 09 de janeiro de 2001. Estabelece o Plano Nacional de Educação. Brasília, 10 jan. 2001. Disponível em: http://www.planalto.gov.br/ccivil_03/leis/ leis_2001/110172.htm. Acesso em: 30 jun. 2019.

BRASIL.Leino 13.005, de 25 de junho de 2014. Aprova o Plano Nacional de Educação-PNE e dá outras providências. Brasília: 25 jun. 2014. Disponível em: https://www2.camara. leg.br/legin/fed/lei/2014/lei-13005-25-junho-2014-778970-publicacaooriginal144468-pl.html. Acesso em: 30 jun jul. 2019.

BRASIL. Ministério da Educação. Secretaria de Educação Básica. Base Nacional Comum Curricular. Diretoria de Currículos e Educação Integral. Brasília: MEC, 2019a. 
BRASIL. Ministério da Educação. Secretaria de Educação Básica. Diretrizes Curriculares Nacionais Gerais da Educação Básica. Diretoria de Currículos e Curriculares Nacionais Gerais da Educação Básica Educação Integral. Brasília: MEC, SEB, DICEI, 2013.

BRASIL. Ministério da Educação. Secretaria de Alfabetização. PNA Política Nacional de Alfabetização/Secretaria de Alfabetização. - Brasília: MEC, SEALF, 2019b.

BRASIL. Parâmetros Curriculares Nacionais/ Ensino Fundamental ( $1^{\mathrm{a}}$ a $4^{\mathrm{a}}$ ). Língua Portuguesa. Brasília: Ministério da Educação e do Desporto, 1997.

BRASIL. Resolução no 7, de 14 de dezembro de 2010. Diretrizes Curriculares para o Ensino de 9 (nove) anos. Resolução CNE/CEB. Diário oficial da União, Brasília, 15 de dezembro de 2010.

BRASIL. Senado Federal. Lei de Diretrizes e Bases da Educação Nacional: no 9394/96. Brasília: 1996.

CASTILHO, R. Direitos humanos. 2. ed. São Paulo: Saraiva, 2013.

DERISSO, J. L. Construtivismo, pós-modernidade e decadência ideológica. In: MARTINS, L. M.; DUARTE, N. (orgs.). Formação de professores: limites contemporâneos e alternativas necessárias. São Paulo: Cultura Acadêmica, 2010.

DUARTE, N.; MARTINS, L. M. As contribuições de Aleksei Nikolaevich Leontiev para o entendimento da relação entre educação e cultura em tempos de relativismo pós-moderno. In: FERRO, O. M. R.; LOPES, Z. A. (Org.). Educação e Cultura: Lições históricas do universo pantaneiro. Campo Grande: UFMS, 2013. p.43-79.

DUARTE, N. As pedagogias do "aprender a aprender" ealgumas ilusões da assim chamada sociedadedo conhecimento. Revista Brasileira de Educação, Belo Horizonte, n. 18, p. 3540, 2001.

FREIRE, P.; MACEDO, D. Alfabetização: leitura do mundo, leitura da palavra. Rio de Janeiro: Paz \& Terra, 1994.

FREIRE, P. Pedagogia da autonomia: saberes necessários à prática educativa. 28. ed. São Paulo: Paz e Terra, 2003.

GONÇALVES, F. C. Alfabetização sob o olhar dos alfabetizadores: um estudo sobre essencialidades, valorações, fundamentos e ações no ensino da escrita na escola. 2011. 281f. Dissertação (Mestrado em Linguística) UFSC, Florianópolis. 2011

GONTIJO, C. M. M. O processo de alfabetização: novas contribuições. São Paulo: Martins Fontes, 2002.

LEONTIEV, A. N. Atividade, consciência y personalidad. Buenos Aires: Ciências Del Hombre, 1983.

LURIA, A. R. O desenvolvimento da escrita na criança. In: VYGOTSKY, L. S. et al. Linguagem, desenvolvimento e aprendizagem. São Paulo: Ícone/EDUSP, 1988. 
MACIEL, L. C.; LUCIO, F. I. P. (org.) Alfabetização e letramento na sala de aula. 2. ed. Belo Horizonte. Autêntica Editora: Ceale, 2009.

MARTINS, L. M. O desenvolvimento do psiquismo e a educação escolar: contribuições à luz da psicologia histórico-cultural e da pedagogia histórico-crítica. Campinas: Autores Associados, 2013.

MORTATTI, M. R. L. Alfabetização no Brasil: conjecturas sobre as relações entre políticas públicas e seus sujeitos privados.Revista Brasileira de Educação, v. 15 n. 44 maio/ ago. 2010, p. 329-410.

MORTATTI, M. R. L.. Histórias dos métodos de alfabetização no Brasil. Conferência proferida durante o Seminário "Alfabetização e Letramento em debate", promovido pelo Departamento de Políticas de Educação Infantil e Ensino Fundamental da Secretaria de Educação Básica do Ministério da Educação, realizado em Brasília, em 27/04/2006.

MORTATTI, M. R. L. Letrar é preciso, alfabetizar não basta ... mais? In: SCHOLZE, L.; ROSING, T.M.K. (Org.). Teorias e práticas de letramento. Brasília: INEP; Passo Fundo; EdUOF, 2007.

OLIVEIRA, M. M. C.Concepções e fundamentos do Pacto Nacional pela Alfabetização na idade certa e seus desdobramentos na formação de alfabetizadores na perspectiva de uma alfabetização emancipatória em Xaxim/SC. Dissertação (Mestrado em Educação) Francisco Beltrão: Universidade Estadual do oeste do Paraná, 2016.

ORGANIZAÇÃO DAS NAÇÕES UNIDAS. Declaração Universal dos DireitosHumanos, 1948. Disponível emhttps://www.unicef.org/brazil/declaracao-universal-dos-direitoshumanos. Acesso em: 12 jun. 2019.

PERRENOUD, P. Construir competências desde a escola. Trad. Bruno Charles Magne. Porto Alegre: Artes Médicas Sul, 1999.

ROCHA, L. A.; RIBEIRO, L. M. S. Ensino fundamental de nove anos: um foco na alfabetização. SeminárioGepráxis, Vitória da Conquista - Bahia - Brasil, v. 6, n. 6, p 24042420, 2017.

SEBRA, A. G. S.; DIAS, N. M. Métodos de alfabetização: Delimitação de procedimentos e considerações para uma prática eficaz. Ver. Psicopedagogia, 2011, p. 306-20.

TFOUNI, L. V. Letramento e alfabetização.2. ed. São Paulo: Cortez, 1997.

TRIVIÑOS, A. N. S. Introdução à pesquisa em ciências sociais: a pesquisa qualitativa em educação. 1. ed. São Paulo: Atlas, 2009.

VYGOTSKI, L. S. Pensamento e Linguagem. São Paulo: Martins Fontes, 1993.

VYGOTSKI, L. S. Obras Escogidas. v. III. Madrid: Visor, 2000.

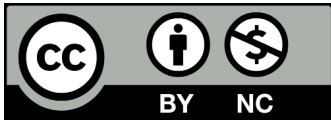

Data de submissão: 02/06/2020

Data de aceite: 06/06/2020 